\title{
Ablative efficiency of 532-nm laser vaporization compared to transurethral resection of the prostate: results from a prospective three-dimensional ultrasound volumetry study
}

\author{
Thomas Hermanns • Oliver Gross • Benedikt Kranzbühler • Lukas J. Hefermehl • \\ Cédric Poyet • Alexander Müller • Stanley A. Yap • Maurice S. Michel • \\ Daniel Eberli • Michael Müntener • Matthias Zimmermann • Tullio Sulser • \\ Hans-Helge Seifert
}

Received: 14 July 2013/Accepted: 23 October 2013/Published online: 31 October 2013

(C) Springer-Verlag Berlin Heidelberg 2013

\begin{abstract}
Purpose To assess and compare postoperative prostate volume changes following 532-nm laser vaporization (LV) and transurethral resection of the prostate (TURP). To investigate whether differences in volume reduction are associated with differences in clinical outcome.

Methods In this prospective, non-randomized study, 184 consecutive patients undergoing $120 \mathrm{~W}$ LV $(n=98)$ or TURP $(n=86)$ were included. Transrectal three-dimensional ultrasound and planimetric volumetry of the prostate were performed preoperatively, after catheter removal, 6 weeks, 6 and 12 months. Additionally, clinical outcome
\end{abstract}

Thomas Hermanns and Oliver Gross have contributed equally to this work.

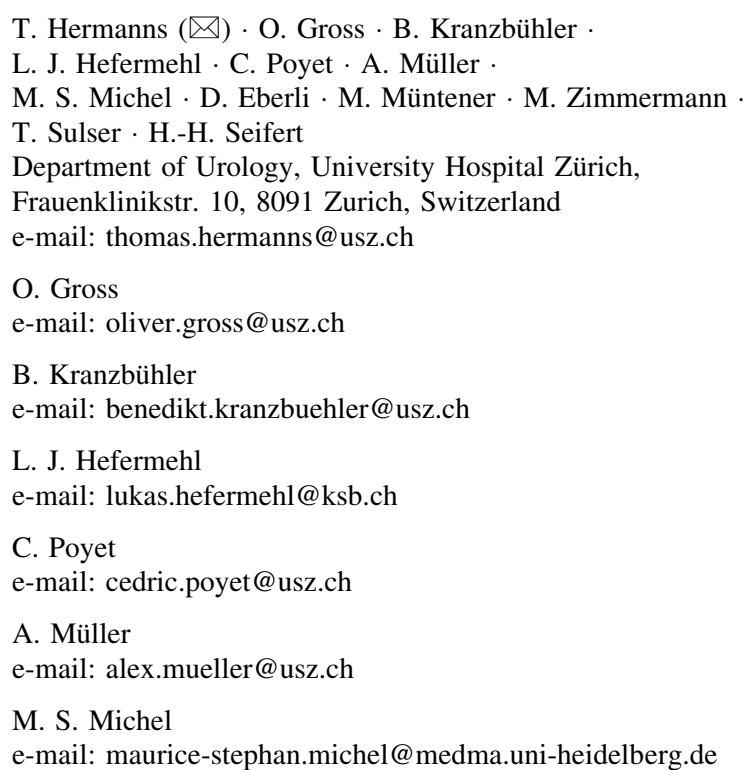

parameters were recorded. Mann-Whitney $U$ test and analysis of covariance were utilized for statistical analysis. Results Postoperatively, a significant prostate volume reduction was detectable in both groups. However, the relative volume reduction was lower following LV (18.4 vs. $34.7 \%, p<0.001)$. After 6 weeks, prostate volumes continued to decrease in both groups, yet differences between the groups were less pronounced. Nonetheless, the relative volume reduction remained significantly lower following LV (12 months 43.3 vs. $50.3 \%, p<0.001$ ). All clinical outcome parameters improved significantly in both groups. However, the maximum flow rate $\left(Q_{\max }\right)$ and prostate-specific antigen (PSA) reduction were significantly lower following LV. Subgroup analyses revealed significant differences only if the initial prostate volume was $>40 \mathrm{ml}$. Re-operations were necessary in three patients following LV.

D. Eberli

e-mail: daniel.eberli@usz.ch

M. Müntener

e-mail: michael.muentener@triemli.zuerich.ch

M. Zimmermann

e-mail: matthias.zimmermann@triemli.zuerich.ch

T. Sulser

e-mail: tullio.sulser@usz.ch

H.-H. Seifert

e-mail: hans-helge.seifert@hbh-kliniken.de

T. Hermanns · S. A. Yap

Division of Urology, Department of Surgical Oncology, Princess

Margaret Cancer Centre, University of Toronto, Toronto,

Canada

e-mail: yapsat@gmail.com

M. S. Michel

Department of Urology, Mannheim Medical Center, University of Heidelberg, Mannheim, Germany 
Conclusions The modest but significantly lower volume reduction following $\mathrm{LV}$ was associated with a lower PSA reduction, a lower $Q_{\max }$ and more re-operations. Given the lack of long-term results after $\mathrm{LV}$, our results are helpful for preoperative patient counseling. Patients with large prostates and no clear indication for the laser might not benefit from the procedure.

Keywords Benign prostatic hyperplasia - Laser vaporization - Laser prostatectomy · Transurethral resection of prostate - Ultrasound of the prostate

\section{Introduction}

The 532-nm laser technique has emerged as a viable surgical option to treat prostatic bladder outlet obstruction with the promise of decreasing morbidity. This is particularly relevant in high-risk cardiovascular patients and in individuals with imperative indications for anti-coagulation or platelet inhibition medication [1].

Good functional short- to mid-term results have consistently been reported for the first-generation $80 \mathrm{~W}$ laser $[2,3]$. However, long-term results are still lacking and high re-treatment rates may indicate that tissue ablation was inadequate using this laser [4]. The second-generation $120 \mathrm{~W}$ laser is characterized by improved tissue ablative properties [5, 6]. A lower perioperative morbidity and a clinical outcome comparable to TURP have been demonstrated in multiple trials [3, 7]. However, long-term results for the 120-W laser are also unknown [8], and higher retreatment rates compared to TURP have already been reported particularly for patients with large prostates [9, 10].

The extent of tissue ablation influences the overall and long-term effectiveness of de-obstructive operations of the prostate, but has yet to be characterized for $\operatorname{LV}[11,12]$. Prostatic ultrasound is an appealing modality to investigate volume changes in the prostate following LV. Conventional biplane ultrasound volumetry is accurate in measuring non-operated prostates [13]. However, precise measurements of a prostate with a postoperative central ablation cavity are not possible using this technique.

In the present investigation, planimetric volumetry following transrectal three-dimensional (3D) ultrasound of the prostate was performed to compare postoperative changes in prostate volumes after LV and TURP.

\section{Patients and methods}

This prospective, non-randomized study was performed in a tertiary referral center. Consecutive patients undergoing either 532-nm LV or conventional monopolar TURP of the prostate between April 2008 and December 2011 were evaluated for study participation. Exclusion criteria included known prostate cancer or use of 5-alpha-reductase inhibitors. Choice of surgery was at the discretion of the attending urologist who conducted the initial clinical assessment. In general, LV was preferred in patients with cardiovascular comorbidities, undergoing anti-coagulation or anti-platelet therapy, or with a particular interest in LV. Approval from local ethics committee was obtained. All patients provided written informed consent.

Preoperatively, the patients underwent transrectal ultrasound of the prostate using a Pro Focus 2202 ultrasound scanner (BK Medical, Denmark). The ultrasound probe was coupled to a UA0513 rotational magnetic wheel mover (BK Medical) to generate 3D images of the prostate. Additionally, patients were asked to complete the International Prostate Symptom Score (IPSS) questionnaire. Uroflowmetry was performed, and post-micturition residual volume was measured. The preoperative blood work included a prostate-specific antigen (PSA) test.

All operations were performed by experienced $(>100$ previous procedures) staff surgeons (LV $85 \%$, TURP $69 \%$ ) or by senior residents (LV $15 \%$, TUR $31 \%$ ) in form of a supervised teaching operation. Laser vaporization was performed as described previously [14] using the 120-W GreenLight HPS $^{\mathrm{TM}}$ laser (American Medical Systems ${ }^{\circledR}$, Minnetonka, USA) and a 24F continuous flow Iglesias laser resectoscope (Karl Storz GmbH, Tuttlingen, D). Monopolar TURP was performed in a classical manner [15] using a 160-W ICC 350 generator (Erbe Elektromedizin GmbH, Tübingen, D) and a $26 \mathrm{~F}$ continuous flow Iglesias resectoscope (Karl Storz). In general, resection was performed until visualization of a wide-open prostatic cavity and an unobstructed view from the verumontanum into the bladder. At the conclusion of the procedure, a $20 \mathrm{~F}$ irrigation catheter was inserted and continuous saline irrigation was initiated. The total laser energy (LV), weight of the removed tissue (TURP) and operative time were recorded.

Uroflowmetry, residual volume measurement and 3D ultrasound were performed following catheter removal. Follow-up visits took place after 6 weeks, 6 months and 12 months. At each visit, 3D ultrasound, uroflowmetry, residual volume measurements and a PSA test were performed. The IPSS questionnaire was completed, and the patients were specifically asked to report symptoms of dysuria.

Planimetric volumetry of the prostate was performed on the generated 3D images using BK-3D-View software (BK Medical). For this purpose, the surface of the prostate was manually encircled at each $2-\mathrm{mm}$ section in the sagittal plane of the prostate. The software calculated the total prostate volume from all encircled sections. Two 
Table 1 Baseline characteristics (a), intra- and perioperative (b) and postoperative parameters (c)

\begin{tabular}{|c|c|c|c|}
\hline & LV & TURP & $p$ value \\
\hline \multicolumn{4}{|l|}{ (a) Baseline } \\
\hline Number of patients & 98 & 86 & \\
\hline Age (years) & $70(49-86)$ & $65(46-84)$ & $<0.001^{*}$ \\
\hline Prostate volume $(\mathrm{ml})$ & $\begin{array}{l}48.2 \\
\quad(21.6-170.6)\end{array}$ & $\begin{array}{l}45.7 \\
\quad(17.5-128.5)\end{array}$ & 0.15 \\
\hline PSA (ng/ml) & $\begin{array}{l}3.98 \\
(0.29-34.6)\end{array}$ & $\begin{array}{l}3.51 \\
\quad(0.31-23.5)\end{array}$ & 0.28 \\
\hline \multicolumn{4}{|l|}{ IPSS } \\
\hline Symptom score & $18(2-32)$ & $19(3-35)$ & 0.1 \\
\hline QoL domain & $4(0-6)$ & $5(0-6)$ & $0.01 *$ \\
\hline$Q_{\max }(\mathrm{ml} / \mathrm{s})$ & $9.6(2.3-21.9)$ & $9.3(1.0-30.9)$ & 0.95 \\
\hline Residual volume (ml) & $80(0-650)$ & $65(0-1400)$ & 0.25 \\
\hline Indwelling catheter $(n)$ & $24(24.5 \%)$ & $16(18.6 \%)$ & 0.37 \\
\hline ASA score & & & 0.13 \\
\hline I & $4(4 \%)$ & $6(7 \%)$ & \\
\hline II & $77(79 \%)$ & $71(83 \%)$ & \\
\hline III & $17(17 \%)$ & $9(10 \%)$ & \\
\hline Coagulation modifiers $(n)$ & $64(65.3 \%)$ & $4(4.7 \%)$ & $<0.001^{*}$ \\
\hline Acetylsalicylic acid $(n)$ & $46(46.9 \%)$ & $4(4.7 \%)$ & \\
\hline Clopidogrel $(n)$ & $10(10.2 \%)$ & $0(0 \%)$ & \\
\hline Coumarin $(n)$ & $22(22.4 \%)$ & $0(0 \%)$ & \\
\hline Dual therapy $(n)$ & $14(14.3 \%)$ & $0(0 \%)$ & \\
\hline \multicolumn{4}{|l|}{ (b) Intra- and perioperative } \\
\hline Operative time (min) & $86(35-180)$ & $70(20-165)$ & $0.001 *$ \\
\hline Blood transfusion $(n)$ & $0(0 \%)$ & $0(0 \%)$ & n.a. \\
\hline $\begin{array}{l}\text { Duration of catheterization } \\
\text { (days) }\end{array}$ & $2(1-22)$ & $3(2-16)$ & $<0.001^{*}$ \\
\hline Re-catheterization $(n)$ & $15(15.3 \%)$ & $10(11.6 \%)$ & 0.5 \\
\hline Urinary retention $(n)$ & $9(9.2 \%)$ & $9(10.5 \%)$ & \\
\hline Persistent hematuria $(n)$ & $2(2 \%)$ & $0(0 \%)$ & \\
\hline $\begin{array}{l}\text { Residual volume } \\
>300 \mathrm{ml}(n)\end{array}$ & $3(3.1 \%)$ & $0(0 \%)$ & \\
\hline $\begin{array}{l}\text { Stress urinary } \\
\text { incontinence }(n)\end{array}$ & $1(1 \%)$ & $1(1.1 \%)$ & \\
\hline \multicolumn{4}{|l|}{ (c) Postoperative } \\
\hline $\begin{array}{l}\text { Urinary tract infection } \\
(6 \text { weeks; } n)\end{array}$ & $9(9.2 \%)$ & $1(1.1 \%)$ & $0.02 *$ \\
\hline \multicolumn{4}{|l|}{ Dysuria $(n)$} \\
\hline 6 Weeks & $23(23.5 \%)$ & $27(31.3 \%)$ & 0.25 \\
\hline 6 Months & $3(3.4 \%)$ & $2(2.7 \%)$ & 1.0 \\
\hline 12 Months & $2(2.6 \%)$ & $3(4.4 \%)$ & 0.7 \\
\hline Urethral stricture $(n)$ & $0(0 \%)$ & $3(4.4 \%)$ & 0.1 \\
\hline Re-operation $(n)$ & $3(3.4 \%)$ & $0(0 \%)$ & 0.25 \\
\hline
\end{tabular}

Data presented as median (range) or number (percent)

PSA prostate-specific antigen, IPSS International Prostate Symptom Score, $Q o L$ quality of life, $Q_{\max }$ maximum flow rate, $A S A$ score American Society of Anesthesiology Score

* Indicates a statistically significant difference between the two groups

investigators (OG, BK) performed all measurements without knowledge of the patients' identity and treatment allocation. A separate investigator (TH) controlled and approved each measurement for the final analysis.
All data are presented as median and range. Statistical analysis was performed using IBM SPSS Statistics version 20 (IBM, Armonk, USA) and SAS version 9.2 (SAS Institute Inc, Cary, USA). The Fisher's exact test and the Mann-Whitney $U$ test were used to compare nominal and continuous variables between the treatment arms. Analysis of covariance (ANCOVA) was utilized to compare posttreatment volumes while accounting for variability in pretreatment volumes. The Wilcoxon signed rank test was used to compare continuous variables within a treatment arm at the different follow-up visits. All $p$ values $<0.05$ were considered statistically significant.

\section{Results}

A total of 184 patients were enrolled in this study. Ninetyeight patients (53\%) underwent LV and 86 patients (47\%) TURP. The baseline characteristics of all patients are presented in Table 1. The preoperative prostate volume, maximum flow rate $\left(Q_{\max }\right)$, residual volume and IPSS were not significantly different between the groups. Patients in the LV group were significantly older, had better results in the quality-of-life domain of the IPSS score, were more often undergoing anti-coagulation or anti-platelet treatment and more often were classified as ASA III. A significant difference in the ASA score distribution was not detectable between the groups. All patients underwent a preoperative, initial postoperative and 6 weeks assessment. A total of $162(88 \%)$ and $146(79.3 \%)$ patients were available for the evaluation after 6 and 12 months, respectively (Fig. 1 for details). The final attrition rate was $20.7 \%$ (LV $20.4 \%$, TURP $20.9 \%$ ).

Table 1 summarizes the intra- and perioperative results. The operative time was significantly longer in the LV group. In the LV group, significant differences in the operative time between patients undergoing anti-coagulation or anti-platelet treatment and no such treatment were not detectable (data not shown). During LV, a median energy of $250 \mathrm{~kJ}(39-636 \mathrm{~kJ})$ was applied. The median weight of the resected tissue in the TURP group was $17 \mathrm{~g}$ (5-67 g). Major complications did not occur in either group.

At the time of catheter removal, a significant reduction in total prostate volume was detected in both groups. However, the remaining prostate volume was significantly higher following $\mathrm{LV}$, even after accounting for preoperative volume (Table 2). Accordingly, the relative volume reduction was significantly lower in the LV group (18.4 vs. $34.7 \%, p<0.001$; Fig. 2a). After 6 weeks, the prostate volume in the LV group continued to decrease. However, the remaining prostate volume (Table 2) and the relative volume reduction (Fig. 2a) remained significantly different 


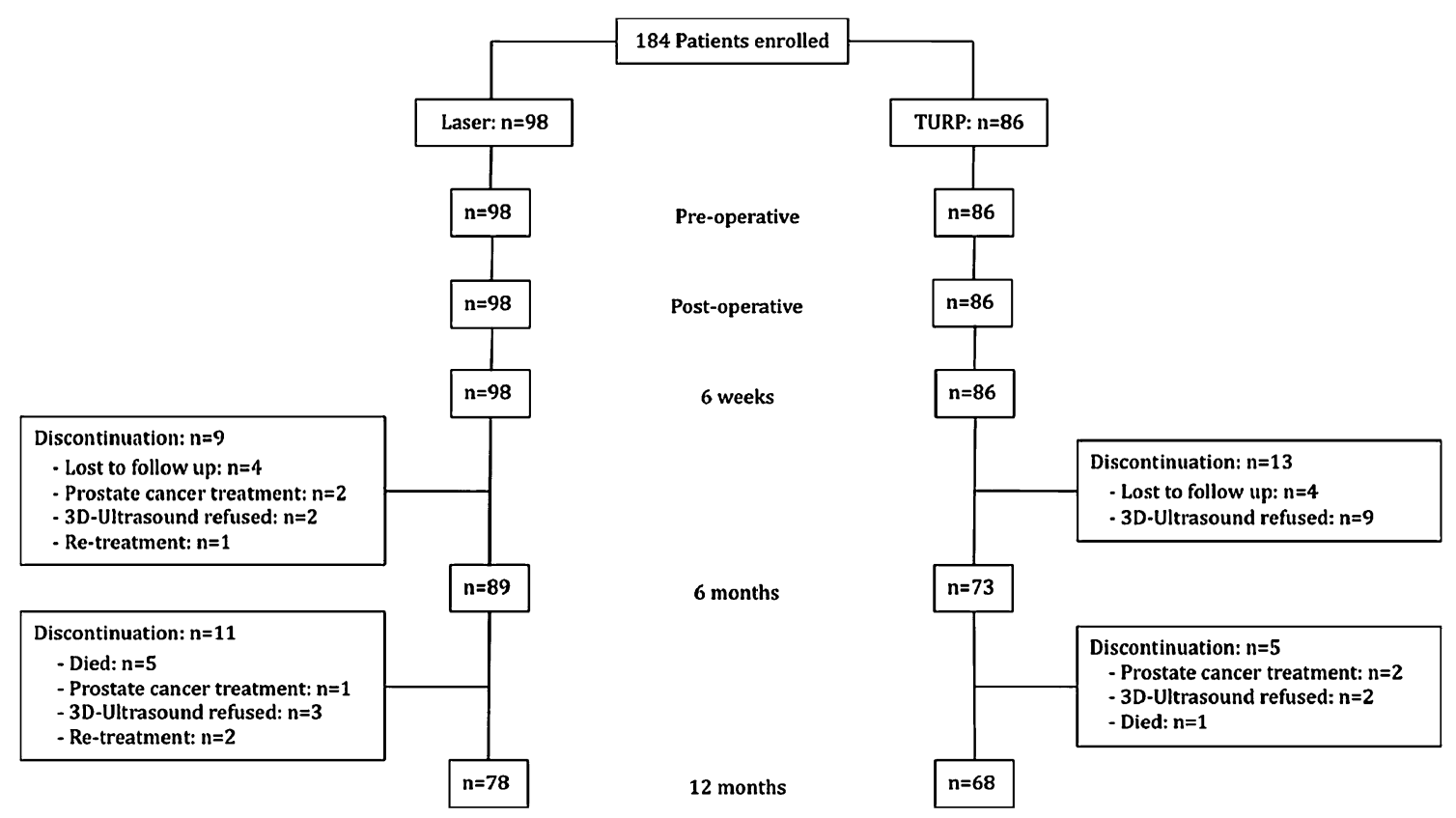

Fig. 1 Study profile

Table 2 Pre- and postoperative prostate volumes

\begin{tabular}{lllll}
\hline & LV & TURP & $p$ (Mann-Whitney) & $p$ (ANCOVA) \\
\hline Preoperative & $48.2(21.6-170.6)$ & $45.7(17.5-128.5)$ & 0.15 & n.a. \\
Postoperative & $40.7(14.9-138.6)$ & $27.5(11.2-90.1)$ & $<0.001^{*}$ & $<0.001^{*}$ \\
6 Weeks & $31.7(10.8-126.2)$ & $24.4(11.3-92.7)$ & $<0.001^{*}$ & $<0.001^{*}$ \\
6 Months & $28.4(10.1-119.1)$ & $20.6(10.1-87.9)$ & $<0.001^{*}$ & $<0.001^{*}$ \\
12 Months & $30(10-123.6)$ & $21.0(8-89)$ & $<0.001^{*}$ & $<0.001^{*}$ \\
\hline
\end{tabular}

Data presented as median (range)

* Indicates a statistically significant difference between the two groups

between the groups. Between 6 weeks and 6 months, a further significant decrease in volume was detected in both groups (Wilcoxon test $p<0.001$ ). Between 6 and 12 months, significant changes in prostate volume were no longer detectable in either group (Wilcoxon $p=0.16$ and 0.06 , respectively). The differences in the relative volume reduction between the groups were still statistically significant after 6 months (39.1 vs. $49.1 \%)$ and 12 months (43.3 vs. $50.3 \%$; Fig. 2a).

Subgroup analysis was performed to test the assumption that LV might be more efficient in smaller prostates. For this purpose, patients were dichotomized based on their initial prostate volume. We found that significant differences in the final relative volume reduction between LV and TURP were only detectable if the initial prostate volume was greater than $40 \mathrm{ml}$ (Fig. 2b-c).

Another subgroup analysis was performed to investigate if volume reduction after $\mathrm{LV}$ is lower in patients undergoing anti-coagulation or anti-platelet treatment compared to patients without any treatment. We were not able to identify significant differences between the two groups at any follow-up visit. The relative volume reduction in the group of patients undergoing treatment was even slightly greater compared to the patients without treatment (data not shown).

Figure $2 \mathrm{~d}$ shows the relative reduction of the PSA value, which was significantly lower following $\mathrm{LV}$ at the conclusion of the study (12 months). After 12 months, the median PSA value in the LV group was $1.6 \mathrm{ng} / \mathrm{ml}$ $(0.13-14.2 \mathrm{ng} / \mathrm{ml})$ and in the TURP group $1.0 \mathrm{ng} / \mathrm{ml}$ $(0.15-24.1 \mathrm{ng} / \mathrm{ml})$. This difference was also statistically significant $(p<0.001)$.

Figure $2 \mathrm{e}-\mathrm{h}$ illustrates the postoperative changes in clinical parameters, which were all significantly improved at the first postoperative assessment. Apart from a significantly lower maximum flow rate in the LV group after 

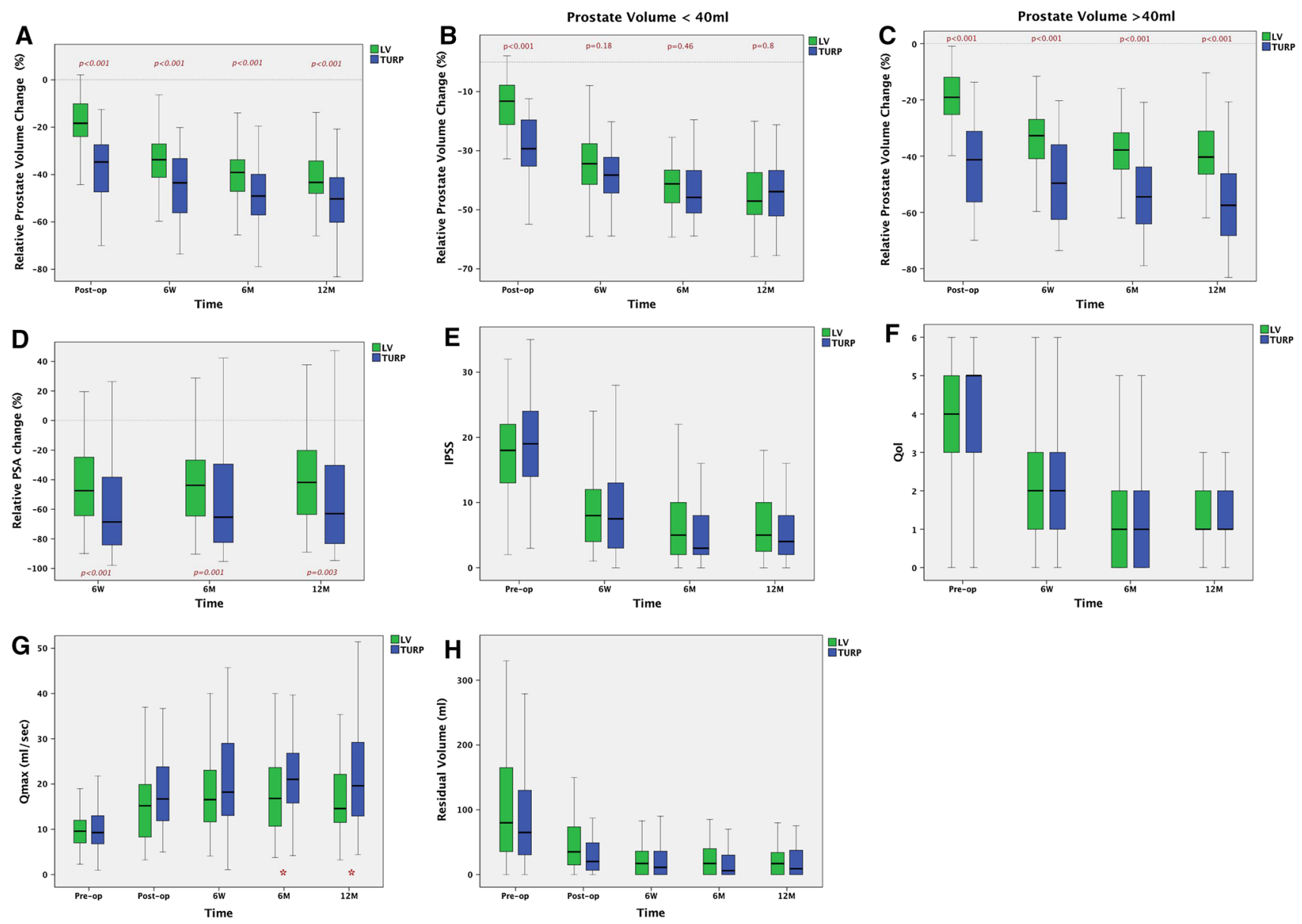

Fig. 2 Boxplots showing the relative postoperative changes in the prostate volume in the two groups (a), the relative postoperative changes in the prostate volume after LV and TURP for two subgroups of patients with an initial prostate volume of less (b) and more than $40 \mathrm{ml}$ (c), respectively; the relative postoperative changes in the prostate-specific antigen (PSA) in the two groups (d) and the postoperative changes in (e) the International Prostate Symptom

6 months (16.8 vs. $21.1 \mathrm{ml} / \mathrm{s}, p=0.02)$ and 12 months (14.6 vs. $19.6 \mathrm{ml} / \mathrm{s}, p=0.04$ ), no significant differences between groups were detected.

In the prostate volume subgroup analysis, significant differences in the clinical parameters and the PSA reduction were also only detectable in the high-volume group. In this group, improvement of the $Q_{\max }$ after 6 months $(p=0.004$, data not shown) and relative reduction of the PSA at each follow-up visit $(p<0.001$, data not shown) were less pronounced following LV.

Further postoperative results of the entire cohort are displayed in Table 1. Re-operation was necessary in none of the TUR patients but in three LV patients. Two patients (initial prostate volumes 32.9 and $48.9 \mathrm{ml}$ ) had obstructive apical tissue, which was resected after 4 and 6 months, respectively. Another patient with persistent obstructive symptoms underwent re-TURP after 3 months. This patient
Score (IPSS), (f) the quality-of-life domain of the IPSS (QoL), (g) the peak urinary flow rate $\left(Q_{\max }\right)$ and $(\mathbf{h})$ the residual volume In both groups, the outcome parameters improved significantly after the operations. The only statistically significant difference between the two groups was detectable for the peak urinary flow rate after 6 and 12 months (Asterisks). All boxplots represent the median, interquartile range and $\pm 1.5 x$ interquartile range

had an initial prostate volume of $57.1 \mathrm{ml}$, and the absolute and relative volume reduction after 6 weeks was $17 \mathrm{ml}$ and $31 \%$, respectively. During re-TURP, $11.2 \mathrm{~g}$ were removed.

\section{Discussion}

This first ever study using 3D ultrasound volumetry to investigate postoperative volume changes in the prostate revealed a lower volume reduction following 532-nm LV compared to TURP. In the past, several minimally invasive alternatives to TURP were abandoned due to insufficient tissue ablation, which resulted in higher re-treatment rates compared to the conventional technique $[12,16]$. Knowledge of postoperative volume changes can help to better understand procedure-specific side effects and can give an 
indication of the long-term effectiveness of a procedure. Although the final 7-10\% difference in the relative volume reduction was not drastic, it was statistically significant and associated with a lower PSA reduction, a lower maximum flow rate and more re-operations in the LV group. A significant difference in the IPSS/Qol, which is often the primary end point of trials comparing the functional outcome of the two procedures was not detectable in the present investigation.

Additionally, our investigation revealed, for the first time, that a distinct delay in the maximum reduction of the prostate volume occurs regularly after LV. Following catheter removal approximately $70 \%$ of the final volume reduction was detected in the TURP group compared to only $45 \%$ in the LV group. Six weeks after the operation, this clear difference was no longer detectable. This observation supports evidence for significant postoperative prostatic swelling and its subsequent resolution following LV. Swelling of the prostate has been identified after LV in animals [17], but the extent of prostatic swelling associated with LV in humans was, so far, unknown.

Prostate swelling might result in postoperative urinary retention and dysuria, which were identified in the present study and have been previously reported [18]. However, despite the less pronounced delay in volume reduction following TURP, the rate of postoperative dysuria and urinary retention was not significantly lower in the TURP group. Dysuria has been reported to be a typical side effect of LV [18]. Our investigation shows that the rate of postoperative dysuria seems to be comparable after TURP and LV. However, we did not investigate the severity of dysuria in our study, which might be different following the two procedures. From our personal experience, patients with early postoperative severe dysuria are rarely, but more often seen after LV compared to conventional TURP. The higher rate of urinary tract infections after LV might partly be related to a larger amount of residual necrotic tissue after LV. Sloughing of necrotic tissue can also take part in the delayed volume reduction after LV. In general, improvement of postoperative volume reduction was accompanied by an improvement of urinary symptoms, and after 6 months, volume reduction and the clinical parameters remained stable in both groups.

It is not known how much tissue needs to be removed to achieve significant symptom improvement after a deobstructive operation. In some investigations, a strong correlation between the extent of tissue removal and the short-term clinical outcome was detectable, while other studies did not demonstrate this relationship [19-22]. In contrast to the present investigation, earlier studies failed to identify a significantly lower $Q_{\max }$ following LV [3]. Most of these studies enrolled fewer numbers of patients than the present study. Thus, it is possible that these studies were underpowered to detect a difference in this endpoint. However, it is also possible that, e.g., the higher age and differences in bladder function of the patients undergoing $\mathrm{LV}$ in the present study account for this difference.

The subgroup analysis revealed that the effectiveness of LV decreases with an increase in the initial prostate volume. The volume reduction and the $Q_{\max }$ measurements after LV were only significantly lower compared to TURP if the prostate volume was larger than $40 \mathrm{ml}$. It is possible that the surgeons' familiarity with LV in larger prostates is responsible for this difference. However, given the experience status of the surgeons and the fairly low cutoff value of $40 \mathrm{ml}$, it is unlikely that individual size limitations are the main reason for the worse outcome following LV in the higher volume group. Two of the three patients who had a re-operation following LV had a prostate volume larger than $40 \mathrm{ml}$. It has previously been reported that the reoperation rate for larger prostates is significantly higher after LV compared to TURP $[9,10]$.

A potential explanation for the lower volume reduction after LV are residual stromal fibers, which extend into the resection cavity during $L V$ and can impair the vaporization efficiency and, probably even more important, the visual identification of the prostatic capsule for the surgeon [23]. Laser fiber degradation associated with a decrease in power output from the laser fiber can furthermore reduce tissue vaporization and lead to increased tissue coagulation [24]. This effect might be more pronounced in larger prostates, for which the subgroup analysis revealed inferior results.

Planimetric volumetry of the prostate was chosen since it is an adequate technique to measure both preoperative and postoperative prostate volumes. By measuring the prostate volume and not the resection cavity, the results of the measurement remain unaffected by the filling volume of the bladder. Planimetric volumetry of the prostate has been shown to have much lower variability and higher reliability compared to conventional biplane measurements [25]. The accuracy is greater than $95 \%$ when a step size of $4 \mathrm{~mm}$ is used for the measurements [26]. A step size of $2 \mathrm{~mm}$, as chosen in the present investigation, is likely to result in an even higher accuracy.

A drawback of this study is its non-randomized design, which resulted in a higher number of patients under ongoing anti-coagulation or platelet inhibition in the LV group. It is possible that surgeons are more cautious to perform extensive tissue ablation in these patients. Thus, the imbalance between the groups might account to some extent for the differences in volume reduction observed between the two groups. However, our subgroup analysis revealed that the use of coagulation modifiers had no significant impact on the volume reduction in the LV group. Although our study was not powered for this subgroup analysis, it indicates that the imbalance between the groups 
did not generate a significant bias in our study. The moderate attrition rate of $20.7 \%$ is another potential limitation. Patient dropout is an expected issue in this elderly patient population. Comparable rates have been reported even in studies that did not require repeated transrectal ultrasounds $[27,28]$. The dropout rate was similar between the two groups, and we do not expect this to create a specific bias toward either group given that follow-up protocols were identical.

In conclusion, we demonstrated that differences in the volume reduction between LV and TURP were modest but statistically significant. The lower volume reduction after $\mathrm{LV}$ affected, at least to some degree, the short-term outcome and might affect the long-term results. The known advantages of the laser may outweigh the consequences of a lower volume reduction in high-risk patients. However, patients without clear indications for LV and with large prostates should be counseled appropriately prior to selecting this procedure and, depending on their prostate volume, should also be informed about alternative treatment options such as holmium laser enucleation or open surgery.

Acknowledgments The authors acknowledge Ms. Alexandra Veloudios for the excellent organization of the patient care during this study.

\section{References}

1. Descazeaud A, Robert G, Azzousi AR, Ballereau C, Lukacs B, Haillot O, Dumonceau O, Devonec M, Fourmarier M, Saussine C, de la Taille A (2009) Laser treatment of benign prostatic hyperplasia in patients on oral anticoagulant therapy: a review. BJU Int 103(9):1162-1165. doi:10.1111/j.1464-410X.2008.08284.x

2. Bouchier-Hayes DM, Van Appledorn S, Bugeja P, Crowe H, Challacombe B, Costello AJ (2010) A randomized trial of photoselective vaporization of the prostate using the $80-\mathrm{W}$ potassium-titanyl-phosphate laser vs transurethral prostatectomy, with a 1-year follow-up. BJU Int 105(7):964-969. doi:10.1111/j. 1464-410X.2009.08961.x

3. Teng J, Zhang D, Li Y, Yin L, Wang K, Cui X, Xu D (2013) Photoselective vaporization with the green light laser vs transurethral resection of the prostate for treating benign prostate hyperplasia: a systematic review and meta-analysis. BJU Int 111(2):312-323. doi:10.1111/j.1464-410X.2012.11395.x

4. Rieken M, Wyler S, Rentsch C, Bonkat G, Gasser TC, Bachmann A (2009) Long-term results of transurethral KTP-laser vaporisation of the prostate. J Urol Suppl 181(4):767

5. Heinrich E, Wendt-Nordahl G, Honeck P, Alken P, Knoll T, Michel MS, Hacker A (2010) $120 \mathrm{~W}$ lithium triborate laser for photoselective vaporization of the prostate: comparison with 80 W potassium-titanyl-phosphate laser in an ex vivo model. J Endourol 24(1):75-79. doi:10.1089/end2009.0051

6. Te AE (2006) The next generation in laser treatments and the role of the GreenLight high performance system laser. Rev Urol 8(Suppl 3):24-30

7. Pereira-Correia JA, de Moraes Sousa KD, Santos JB, de Morais Perpétuo D, Lopes-da-Silva LF, Krambeck RL, Muller VJ, Vaz FP (2012) GreenLight HPS 120-W laser vaporization vs transurethral resection of the prostate $(<60 \mathrm{~mL})$ : a 2-year randomized double-blind prospective urodynamic investigation. BJU Int 110(8):1184-1189. doi:10.1111/j.1464-410X.2011.10878.x

8. Gravas S, Bachmann A, Reich O, Roehrborn CG, Gilling PJ, De La Rosette J (2011) Critical review of lasers in benign prostatic hyperplasia (BPH). BJU Int 107(7):1030-1043. doi:10.1111/j. 1464-410X.2010.09954.x

9. Al-Ansari A, Younes N, Sampige VP, Al-Rumaihi K, Ghafouri A, Gul T, Shokeir AA (2010) GreenLight HPS 120-W laser vaporization versus transurethral resection of the prostate for treatment of benign prostatic hyperplasia: a randomized clinical trial with midterm follow-up. Eur Urol 58(3):348-355. doi:10. 1016/j.eururo.2010.05.026

10. Hueber PA, Ben-Zvi T, Liberman D, Bhojani N, Gautam G, Deklaj T, Katz M, Zorn KC (2012) Mid term outcomes of initial 250 case experience with GreenLight $120 \mathrm{~W}$-HPS photoselective vaporization prostatectomy for benign prostatic hyperplasia: comparison of prostate volumes $<60 \mathrm{cc}, 60 \mathrm{cc}-100 \mathrm{cc}$ and $>100$ cc. Can J Urol 19(5):6450-6458

11. Aagaard J, Jonler M, Fuglsig S, Christensen LL, Jorgensen HS, Norgaard JP (1994) Total transurethral resection versus minimal transurethral resection of the prostate-a 10-year follow-up study of urinary symptoms, uroflowmetry and residual volume. $\mathrm{Br} \mathrm{J}$ Urol 74(3):333-336

12. Madersbacher S, Marberger M (1999) Is transurethral resection of the prostate still justified? BJU Int 83(3):227-237

13. Tewari A, Indudhara R, Shinohara K, Schalow E, Woods M, Lee R, Anderson C, Narayan P (1996) Comparison of transrectal ultrasound prostatic volume estimation with magnetic resonance imaging volume estimation and surgical specimen weight in patients with benign prostatic hyperplasia. J Clin Ultrasound 24(4):169-174. doi:10.1002/(SICI)1097-0096(199605)24:4<169: AID-JCU2>3.0.CO;2-D

14. Hermanns T, Sulser T, Fatzer M, Baumgartner MK, Rey JM, Sigrist MW, Seifert H-H (2009) Laser fibre deterioration and loss of power output during photo-selective $80-\mathrm{W}$ potassium-titanyl-phosphate laser vaporisation of the prostate. Eur Urol 55(3):679-685

15. Hartung R, May F (2002) Die transurethrale Elektroresektion der Prostata. Aktuel Urol 33(6):469-482

16. de la Rosette J, Collins E, Bachmann A, Choi B, Muir G, Reich O, Gómez-Sancha F, Tabatabaei S, Woo H (2008) Historical aspects of laser therapy for benign prostatic hyperplasia. Eur Urol Suppl 7(4):363-369

17. Kuntzman RS, Malek RS, Barrett DM, Bostwick DG (1997) High-power (60-watt) potassium-titanyl-phosphate laser vaporization prostatectomy in living canines and in human and canine cadavers. Urology 49(5):703-708

18. Ahyai SA, Gilling P, Kaplan SA, Kuntz RM, Madersbacher S, Montorsi F, Speakman MJ, Stief CG (2010) Meta-analysis of functional outcomes and complications following transurethral procedures for lower urinary tract symptoms resulting from benign prostatic enlargement. Eur Urol 58(3):384-397. doi:10. 1016/j.eururo.2010.06.005

19. Agrawal MS, Aron M, Goel R (2005) Hemiresection of the prostate: short-term randomized comparison with standard transurethral resection. J Endourol 19(7):868-872. doi:10.1089/ end.2005.19.868

20. Antunes AA, Srougi M, Coelho RF, Leite KR, Freire G de C (2009) Transurethral resection of the prostate for the treatment of lower urinary tract symptoms related to benign prostatic hyperplasia: how much should be resected? Int Braz J Urol 35(6):683-689, discussion 689-691

21. Chen SS, Hong JG, Hsiao YJ, Chang LS (2000) The correlation between clinical outcome and residual prostatic weight ratio after transurethral resection of the prostate for benign prostatic hyperplasia. BJU Int 85(1):79-82 
22. Hakenberg OW, Helke C, Manseck A, Wirth MP (2001) Is there a relationship between the amount of tissue removed at transurethral resection of the prostate and clinical improvement in benign prostatic hyperplasia. Eur Urol 39(4):412-417

23. Heinrich E, Schiefelbein F, Schoen G (2007) Technique and short-term outcome of green light laser (KTP, 80W) vaporisation of the prostate. Eur Urol 52(6):1632-1637

24. Hermanns T, Strebel DD, Hefermehl LJ, Gross O, Mortezavi A, Muller A, Eberli D, Müntener M, Michel MS, Meier AH, Sulser T, Seifert HH (2011) Lithium triborate laser vaporization of the prostate using the $120 \mathrm{w}$, high performance system laser: high performance all the way? J Urol 185(6):2241-2247. doi:10.1016/ j.juro.2011.02.023

25. Tong S, Cardinal HN, McLoughlin RF, Downey DB, Fenster A (1998) Intra- and inter-observer variability and reliability of prostate volume measurement via two-dimensional and three-dimensional ultrasound imaging. Ultrasound Med Biol 24(5):673-681
26. Aarnink RG, Giesen RJ, de la Rosette JJ, Huynen AL, Debruyne FM, Wijkstra H (1995) Planimetric volumetry of the prostate: how accurate is it? Physiol Meas 16(3):141-150

27. Lukacs B, Loeffler J, Bruyere F, Blanchet P, Gelet A, Coloby P, De la Taille A, Lemaire P, Baron JC, Cornu JN, Aout M, Rousseau H, Vicaut E (2012) Photoselective vaporization of the prostate with GreenLight 120-W laser compared with monopolar transurethral resection of the prostate: a multicenter randomized controlled trial. Eur Urol 61(6):1165-1173. doi:10.1016/j.eururo.2012.01.052

28. Mamoulakis C, Schulze M, Skolarikos A, Alivizatos G, Scarpa RM, Rassweiler JJ, de la Rosette JJ, Scoffone CM (2013) Midterm results from an international multicentre randomised controlled trial comparing bipolar with monopolar transurethral resection of the prostate. Eur Urol 63(4):667-676. doi:10.1016/j. eururo.2012.10.003 